04

\title{
Исследование рельсового электромагнитного источника плазменной струи
}

\author{
(C) А.В. Воронин, В.Ю. Горяинов, В.К. Гусев, А.Н. Новохацкий, С.А. Поняев \\ Физико-технический институт им. А.Ф. Иофрфе РАН, \\ 194021 Санкт-Петербург, Россия \\ e-mail: voronin.mhd@mail.ioffe.ru
}

Поступило в Редакцию 6 февраля 2019 г.

В окончательной редакции 6 февраля 2019 г.

Принято к публикации 13 февраля 2019 г.

Представлены исследования элементов рельсового электромагнитного ускорителя (рельсотрона), направленные на изучение механизма формирования потока плотной и чистой плазмы с большой кинетической энергией. Проведены испытания ускорителя с импульсным напуском газа с различной формой и длиной электродов, а также с дополнительным магнитным полем, создаваемым внешними проводниками с током. Разработана методика контроля параметров плазменной струи на стенде плазменной пушки с применением датчика давления и тепловизора. Исследована зависимость давления потока дейтериевой плазмы от расстояния до ускорителя, проведена оценка кинетической энергии струи.

DOI: 10.21883/JTF.2019.07.47791.39-19

\section{Введение}

Потоки плотной и чистой плазмы с большой кинетической энергией представляют интерес для решения прикладных и фундаментальных задач, например для подачи топлива в термоядерные устройства, а также для облучения и изучения свойств новых материалов при облучении мощными потоками плазмы. Интенсивная инжекция вещества в активную область реактора позволит значительно улучшить энергетические параметры плазмы, прежде всего концентрацию и давление, управлять процессами зажигания, горения и гашения разряда. Эффективность подачи топлива обеспечивается за счет сильной зависимости термоядерной мощности от плотности плазмы $P_{\text {fusion }} \sim n^{2}[1]$.

Существуют различные способы импульсной подачи вещества в термоядерные устройства: центрифуги, пневматические пушки [2,3], плазменные источники типа Маршалла [4], эрозионный источник Бостика [5], компактные торы [6], разряд в капиллярных каналах [7], устройства с плазменным фокусом [8]. Но их практическому использованию препятствует наличие большого количества примесей, возникающих вследствие эрозии электродов, и недостаточная кинетическая энергия инжектируемого вещества. Метод нейтральной инжекции является одним из самых успешных в задаче подачи топлива в реактор, но также имеет ряд ограничений и высокую стоимость аппаратуры [9]. Изучение ускорителей типа „рельсотрон“ проводятся в основном с целью ускорения твердых тел в атмосфере или в среде различных газов. В настоящей работе представлены результаты исследования возможности рельсового электромагнитного ускорителя с целью получения большой кинетической энергии плазменной струи в вакууме.

\section{Экспериментальный стенд}

Исследования рельсотрона проводилось на стенде плазменной пушки. Стенд состоял из вакуумной камеры объемом $2.5 \mathrm{~m}^{3}$, рельсотрона и диагностик для измерения параметров плазменной струи (рис. 1). Стенд позволял присоединять к вакуумному затвору камеры различные варианты плазменных источников. Струя ускоренной плазмы могла свободно вытекать в большой объем камеры стенда без взаимодействия с ее стенками.

Давление плазменной струи на различных расстояниях от источника регистрировалось лабораторным датчиком. Эта методика подробно описана в работе [10]. В отличие от ранее используемых датчиков в работе применялся детектор, надежно экранированный от электромагнитных наводок и потенциала плазменной струи.

На стенде была налажена новая методика измерения поперечного размера и профиля энергии струи с помощью тепловизора FLIR серии SC7300M. C этой целью в вакуумной камере в поперечном сечении струи располагался медный экран с размерами $220 \times 220 \mathrm{~mm}$ толщиной $0.1 \mathrm{~mm}$. На зачерненной теневой стороне экрана регистрировалось поле температур, создаваемое потоком плазмы. Для регистрации поля температур тепловизор располагался с теневой стороны экрана снаружи вакуумной камеры. Регистрация теплового потока осуществлялась через окно из селенида цинка $(\mathrm{SeZn})$. Окно пропускало излучение в видимой и инфракрасной областях спектра. Характерные размеры пятна термограммы с высокой достоверностью характеризовали поперечные размеры струи плазмы в месте ее взаимодействия с экраном. Перемещение экрана вдоль оси струи позволяло измерять зависимость диаметра струи от расстояния до источника. Профиль температуры на экране сохранялся в неизменном виде в течение $\leq 1 \mathrm{~s}$. 


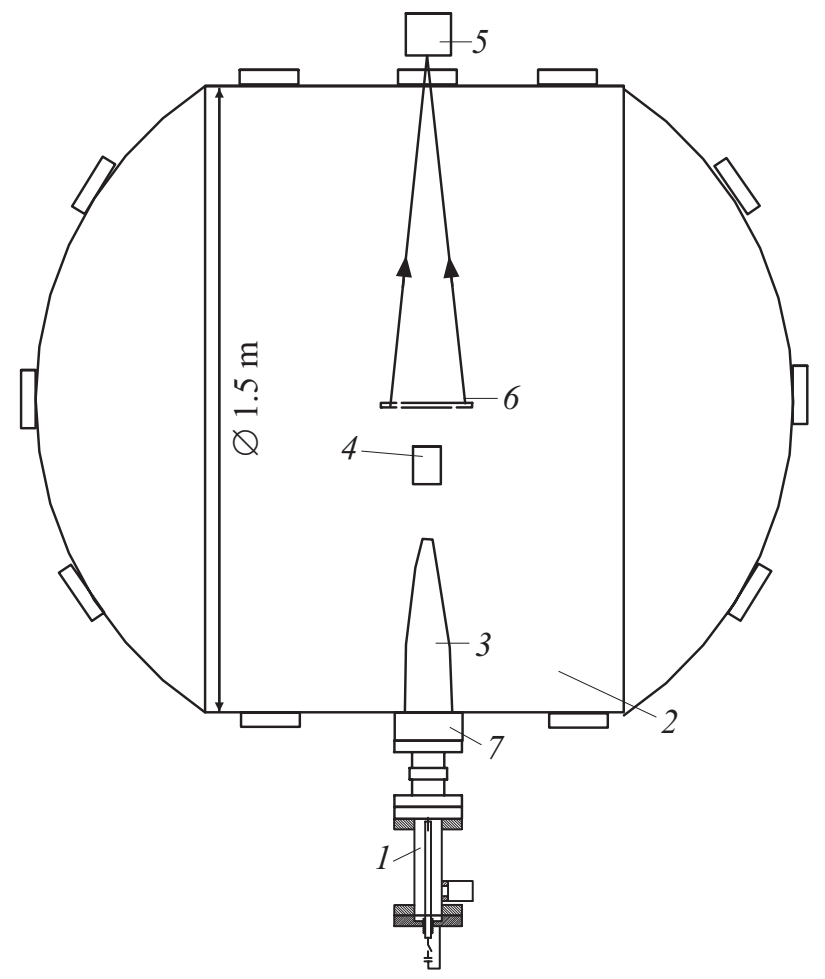

Pис. 1. Схема стенда плазменной пушки с диагностиками: 1 - рельсотрон, 2 - вакуумная камера, 3 - струя плазмы, 4 - подвижный датчик давления, 5 - тепловизор, 6 - подвижный медный экран, 7 - вакуумный затвор.

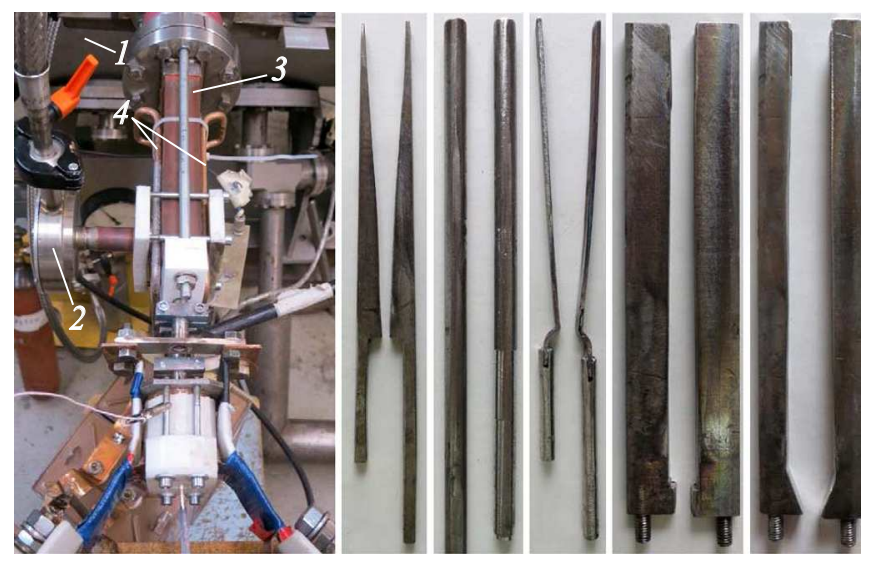

Pис. 2. Лабораторный макет рельсотрона с импульсной подачей рабочего газа, расположенный в керамической вакуумной камере, а также тестированные электроды длиной $180 \mathrm{~mm}$. 1 - вакуумная камера, 2 - импульсный клапан, 3 - керамическая камера рельсотрона, 4 - внешние проводники.

Частота кадров тепловизора составляла $5 \mathrm{~ms}$. Оценка энергии, выделяемой при столкновении струи с экраном, проводилась по формуле

$$
W_{\text {target }}=M \cdot C \cdot T_{\text {mean }},
$$

где $M, C$ и $T_{\text {mean }}-$ масса, удельная теплоемкость материала и средняя температура нагрева экра- на соответственно. Для $C=385 \mathrm{~J} /(\mathrm{kg} \cdot \mathrm{K}), M=S \cdot h \cdot \rho=$ $=0.222 \cdot 10^{-4} \cdot 8930=0.0432 \mathrm{~kg}$, где $S-$ площадь, $h-$ толщина, $\rho$ - плотность экрана, имеем

$$
W_{\text {target }}=0.0432 \cdot 386 T_{\text {mean }}=16.7 T_{\text {mean }} .
$$

На рис. 2 представлен лабораторный макет рельсотрона в керамической вакуумной камере, а также тестируемые электроды. Импульсный напуск дейтерия $\left(\sim 10^{20}\right.$ частиц) в ускоритель производился с помощью клапана электродинамического типа в течение $\sim 300 \mu \mathrm{s}$ перед началом разряда. Питание рельсотронного ускорителя осуществлялось с помощью емкостного накопителя $160 \mu \mathrm{F}$, напряжением до $6 \mathrm{kV}$, током разряда до $120 \mathrm{kA}$ и длительностью импульса $\sim 20 \mu \mathrm{s}$. Выбор максимального рабочего напряжения и тока разряда был обусловлен ограничением поступления примесей с электродов ускорителя.

С целью увеличения ускоряющего магнитного поля рельсотрон был оснащен двумя дополнительными проводниками, расположенными снаружи керамической камеры параллельно электродам ускорителя. Впервые такой рельсотрон уже был успешно применен для ускорения твердых тел [11]. Для эффективного ускорения плазмы длина электродов выбиралась меньше длины внешних проводников и составляла $120 \mathrm{~mm}$. Расстояние между электродами в области напуска газа и на выходе из ускорителя составляли 10 и $20 \mathrm{~mm}$ соответственно. В качестве рабочего газа использовался аргон. В ходе исследований было обнаружено, что кинетическая энергия струи практически не зависела от рода рабочего газа. Поэтому в экспериментах применялся также дейтерий, водород и воздух. Ток во внешних проводниках создавался до начала разряда с помощью конденсаторного накопителя емкостью $200 \mu \mathrm{F}$, напряжением $5 \mathrm{kV}$, и позволял увеличить магнитное поле в зазоре между электродами рельсотрона. Разряд в ускорителе зажигался в момент, когда внешнее поле было максимальным.

\section{Результаты исследования}

В наших экспериментах проводились измерения параметров плазменной струи, создаваемой источником с импульсной подачей дейтерия в керамическую вакуумную камеру рельсотрона. На рис. 3 представлена зависимость давления плазменной струи от расстояния до источника для различных электродов. Видно, что ускоритель со всеми тестированными электродами генерировал струю с давлением, не превышающим 0.3 МРа. С увеличением расстояния между ускорителем и датчиком от 50 до $400 \mathrm{~mm}$ давление значительно уменьшалось с 0.3 до $0.01 \mathrm{MPa}$. Вероятно, взаимодействие непроводящих стенок керамической камеры рельсотрона с разрядом и образование примесей препятствовали ускорению плазмы.

С целью увеличения кинетической энергии струи плазмы было создано дополнительное магнитное поле в зазоре между электродами с помощью внешних 


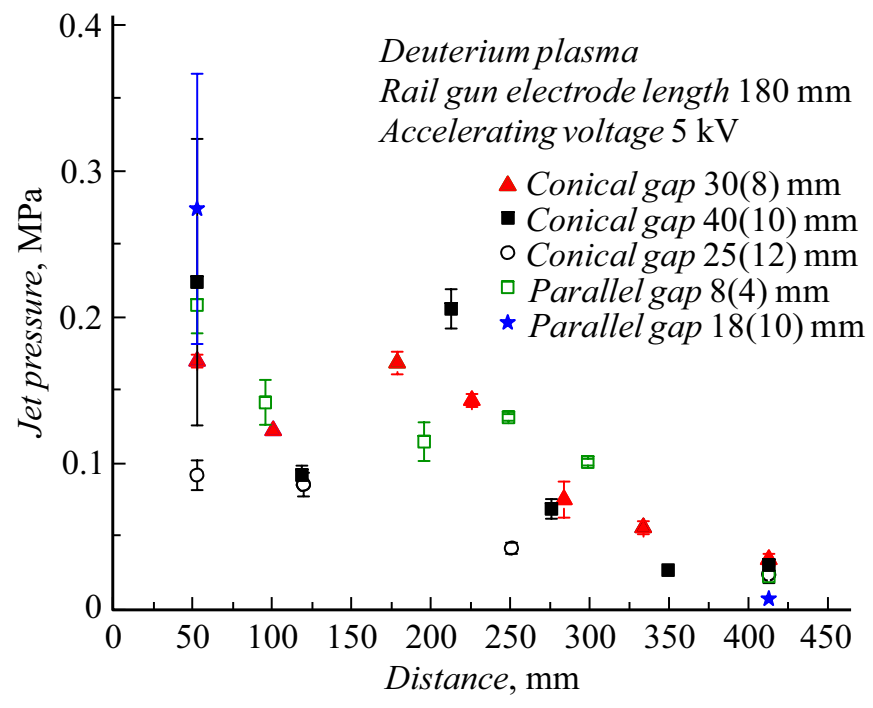

Рис. 3. Зависимость давления струи от расстояния до источника для различных электродов рельсотрона. Зазор между электродами, указанный в скобках, соответствует началу развития разряда.

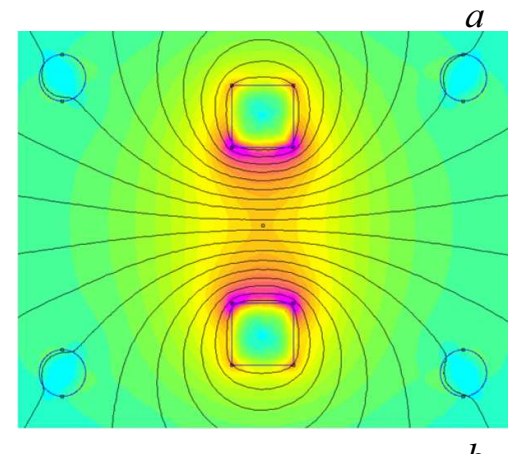

\section{FEMM output}

Point: $x=0, y=0$

$A=0.00030092-\mathrm{I} \cdot 2.649 \mathrm{e}-005 \mathrm{~Wb} / \mathrm{m}$ $|B|=3.04705 \mathrm{~T}$
$B=3.0469+\mathrm{I} \cdot 0$.

$B_{x}=3.0469+\mathrm{I} \cdot 0.0253546 \mathrm{~T}$

$B_{y}=0.00103395+\mathrm{I} \cdot 0.000254436 \mathrm{~T}$
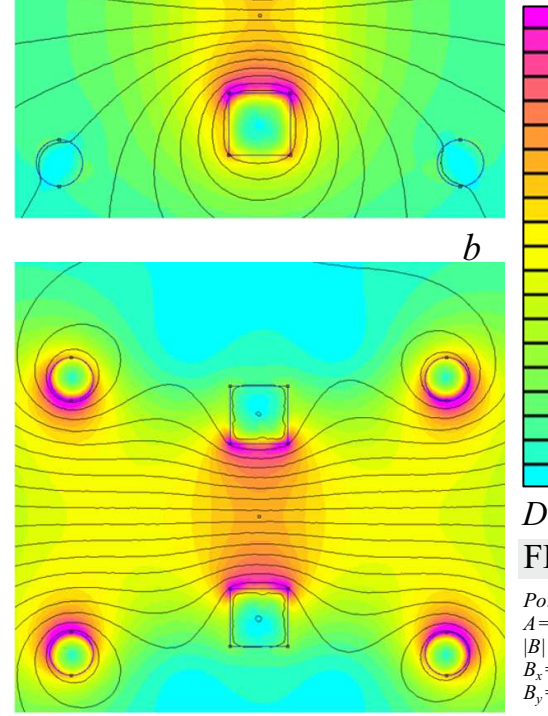

$6.968 \mathrm{e}+000:>7.335 \mathrm{e}+000$
$6.601 \mathrm{e}+000: 6.968 \mathrm{e}+000$ $6.601 \mathrm{e}+000: 6.968 \mathrm{e}+000$
$6.234 \mathrm{e}+000: 6.601 \mathrm{e}+000$
$5.868 \mathrm{e}+000: 6.234 \mathrm{e}+000$ $6.234 \mathrm{e}+000: 6.601 \mathrm{e}+000$
$5.868 \mathrm{e}+000: 6.234 \mathrm{e}+000$ $5.501 \mathrm{e}+000: 5.868 \mathrm{e}+000$ $5.134 \mathrm{e}+000: 5.501 \mathrm{e}+000$ $4.768 \mathrm{e}+000: 5.134 \mathrm{e}+000$ $4.401 \mathrm{e}+000: 4.768 \mathrm{e}+000$ $4.034 \mathrm{e}+000: 4.401 \mathrm{e}+000$ $3.668 \mathrm{e}+000: 4.034 \mathrm{e}+000$ $3.301 \mathrm{e}+000: 3.034 \mathrm{e}+000$ $2.934 \mathrm{e}+000 \cdot 3.368 \mathrm{e}+000$ $2.567 \mathrm{e}+000: 2.934 \mathrm{e}+000$ . $1.201 \mathrm{e}+000: 2.567 \mathrm{e}+000$ $1.834 \mathrm{e}+000: 2.201 \mathrm{e}+000$ $1.467 \mathrm{e}+000: 1.834 \mathrm{e}+000$
$1.101 \mathrm{e}+000: 1.467 \mathrm{e}+000$ $7.339 \mathrm{e}-001: 1.101 \mathrm{e}+000$ $3.672 \mathrm{e}-001: 7.339 \mathrm{e}-001$ $<4.840 \mathrm{e}-004: 3.672 \mathrm{e}-001$ Density plot: $|\mathrm{B}|, \mathrm{T}$ FEMM output

Point: $x=0, y=0$ $A=0.00111784-\mathrm{I} \cdot 4.34869 \mathrm{e}-005 \mathrm{~Wb} / \mathrm{m}$ $|B|=4.94378 \mathrm{~T}$ $B_{\mathrm{r}}=4.94316+\mathrm{I} \cdot 0.0780233 \mathrm{~T}$ $B_{y}=0.00123233+\mathrm{I} \cdot 0.000254836 \mathrm{~T}$

Рис. 4. Результаты расчета магнитного поля в рельсотроне с внешними проводниками: $a$ - витки $0 \mathrm{kA}$, электроды $100 \mathrm{kA}$; $b$ - витки $100 \mathrm{kA}$, электроды $100 \mathrm{kA}$. Расстояние между прямоугольными электродами $20 \mathrm{~mm}$.

проводников с током. Результаты расчета магнитного поля в зазоре между электродами рельсотрона представлены на рис. 4. Видно, что величина поля в зазоре увеличилась с 3 до $5 \mathrm{~T}$ за счет проводников с током, установленных снаружи керамической камеры.
Фотография интегрального во времени свечения плазменной струи, облучающей экран, расположенный в камере стенда, представлена на рис. 5, $a$. Виден факел струи и интенсивное свечение в центре экрана. Термограмма, создаваемая потоком плазменной струи на экране спустя $5 \mathrm{~ms}$ после облучения, представлена на рис. $5, b$. Термограмма характеризовала профиль кинетической энергии и давления струи плазмы в месте ее

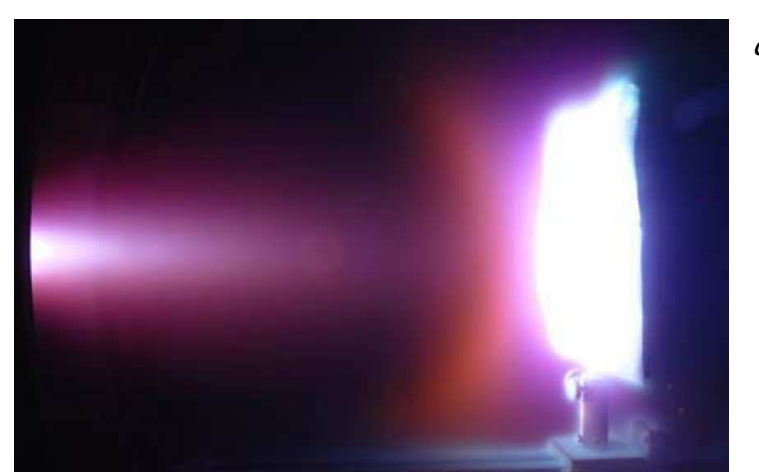

$a$
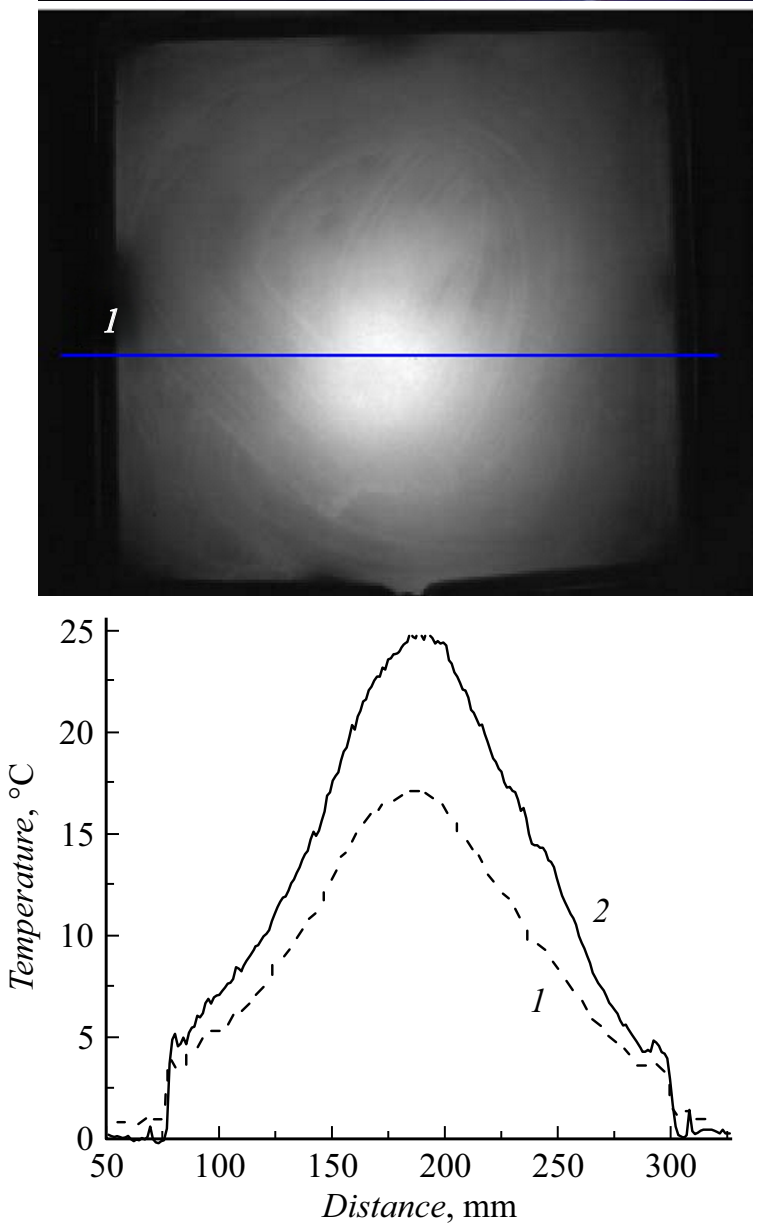

Pис. 5. $a-$ плазменная струя, облучающая экран, расположенный в вакуумной камере; $b-$ термограмма, создаваемая потоком плазменной струи на экране спустя $5 \mathrm{~ms}$ после облучения; $c$ - зависимость температуры экрана от расстояния вдоль выделенного направления, указанного на термограмме: 1 - без внешнего магнитного поля, 2 - с внешним магнитным полем. Расстояние между экраном и ускорителем $970 \mathrm{~mm}$. 
взаимодействия с экраном. Максимальная яркость в центре экрана соответствовала максимальной температуре. Видно также, что пятно было аксиально симметрично. Горизонтальная линия показывала направление, вдоль которого измерялась температура экрана, для случаев, когда ток во внешних проводниках составлял 0 и $100 \mathrm{kA}$ соответственно (рис. 5,c). Видно, что при увеличении магнитного поля в зазоре с 3 до 5 T температура в центре экрана увеличилась с 16 до $25^{\circ} \mathrm{C}$. Также возросла и его средняя температура с 8 до $12^{\circ} \mathrm{C}$. Оценки показали, что при увеличении поля в зазоре выделенная в экране энергия увеличилась со 133.6 до $200.4 \mathrm{~J}$, т. е. с 7 до $10 \%$ от полной энергии конденсаторного накопителя. Диаметр пятна на уровне $T_{0.5 \max }$ составлял $\sim 120 \mathrm{~mm}$ и не зависел от величины магнитного поля. Полученные результаты следует рассматривать как оценку кинетической энергии струи снизу, так как значительная ее доля могла теряться, например, в виде радиационных потерь.

\section{Заключение}

Проведены исследования рельсотронного источника плазмы с импульсным напуском газа, различной формой и длиной электродов, а также с дополнительным магнитным полем, создаваемым внешними проводниками с током. Разработана и налажена новая методика измерения поперечного размера и профиля энергии струи с помощью тепловизора. Получены зависимости давления и диаметра струи дейтериевой плазмы от расстояния до ускорителя. На выходе источника была получена плазма с давлением $\sim 0.3 \mathrm{MPa}$. Повышение магнитного поля в зазоре с 3 до $5 \mathrm{~T}$ между электродами с помощью внешних проводников с током позволило увеличить кинетическую энергию струи плазмы примерно в 1.5 раза без увеличения тока разряда.

\section{Список литературы}

[1] Wesson J. Tokamaks. Oxford, 2004. P. 8-9.

[2] Combs S.K. // Rev. Sci. Instrum. 1993. Vol. 64. N 7. P. 1679 1698.

[3] Drobyshevsky E.M., Zhukov B.G., Sakharov V.A. // IEEE. Trans. Magn. 1995. Vol. 31. N 1. P. 299-302.

[4] Marshall J. // Phys. Fluids. 1960. Vol. 3. P. 134-135.

[5] Voronin A.V., Hellblom K.G. // Plasma Phys. Contr. Fusion. 1999. Vol. 4. P. 293-302.

[6] Perkins L.J., Ho S.K., Hammer J.H. // Nucl. Fusion. 1988. Vol. 28. N 8. P. 1365-1378.

[7] Семенов В.К., Спекторов Л.А. // ЖТФ. 1964. Т. 34. С. $853-$ 860.

[8] Vasiljeva R.P. et al. // Plasma Phys. Contr. Nucl. Fusion Res. 1969. Vol. 2. P. 39-47.

[9] ITER Physics Basis. // Nucl. Fusion. 1999. Vol. 39. N 12. P. 2391-2469.

[10] Воронин А.В., Гусев В.К., Герасименко Я.А., Судьенков Ю.В. // ЖТФ. 2013. Т. 83. Вып. 8. С. 36-42.

[11] Поняев С.А., Резников Б.И., Куракин Р.О., Попов П.А., Жуков Б.Г. // Письма в ЖТФ. 2019. Т. 45. Вып. 2. С. 10-13. 